\title{
Clinical Profile of Coronary Artery Disease In Valvular Heart Disease Undergoing Valve Replacement Surgery
}

\author{
${ }^{1}$ Dr Bornali Dutta, ${ }^{2}$ Dr Harishankar P Singh, ${ }^{3}$ Dr J.C Barkataki, \\ ${ }^{4}$ Dr Farhin Iqbal \\ ${ }^{1}$ Associate Professor Department Of Cardiology Gauhati Medical College, Guwahati Assam, India \\ ${ }^{2}$ Consultant Ashish Hospital Jabalpur, Madhya Pradesh India \\ ${ }^{3}$ Professor And Head Department Of Cardiology Gauhati Medical College, Guwahati Assam, India \\ ${ }^{4}$ Assistant Professor Department Of Cardiology Gauhati Medical College, Guwahati Assam, India
}

\begin{abstract}
:
Introduction: Clinical profile of Coronary artery disease in valvular heart disease undergoing valve replacement surgeryhas not been reported from North Eastern India.

Aim: To study the Clinical profile of Coronary artery disease in valvular heart disease undergoing valve replacement surgery has

Materials And Methods: We prospectively collected data of valvular heart disease above 35 years who were scheduled for valve surgery from December 2011 to November 2013..The baseline clinical characteristics which were analyzed were the age, gender, hypertension (blood pressure >140/90 $\mathrm{mm} \mathrm{Hg}$ and/ or those already taking treatment for hypertension), diabetes mellitus (fasting blood glucose >126 mg/dL and/or postprandial blood glucose $>200 \mathrm{mg} / \mathrm{dL}$ and those who were on treatment for diabetes mellitus), smoking status \&dyslipidemia (cholesterol $>200 \mathrm{mg} / \mathrm{dL}$ and/or triglycerides $>200 \mathrm{mg} / \mathrm{dL}$ and/or,$L D L>130 \mathrm{mg} / \mathrm{dL}$ and/or $H D L<40 \mathrm{mg} / \mathrm{dL}$ ). Selective coronary arteriography was performed by the Judkins technique The patients were divided into two groups based on presence of CAD. A comparasion of clinical paramaters between two groups were obtained

Results: A total of 126 valvular disease cases were included in the study. overall prevalenceof coronary artery disease was $14.28 \%$. Frequency of coronary artery disease among mitral, aortic, and combined mitral and aortic valve lesion is $3.13 \%, 33.33 \%$ and $21.05 \%$ respectively. In comparison to mitral valve disease, aortic valve disease and combined lesion having significantly high chances of coronary artery disease $(p=0.001)$.On comparing the clinical characteristic of patients with CAD from those without having CAD, we observed that , mean age of the patients with coronary artery disease (59.45 \pm 10.58$)$ are significantly high in comparison to without coronary artery disease (48.92 \pm 6.57$)$. Coronary artery disease group also had significantly high prevalence of diabetes mellitus, hypertension, and dyslipidemia ( $p$ value of $<0.001$ for each) and also more likely to present with angina.
\end{abstract}

Conclusion: We conclude that in patients with valvular heart disease undergoing valve replacement surgery, the overall prevalence of CAD is low at 14.28\%.Patients having CAD are more likely to present with angina and have higher prevalence of cardiovascular risk factors.

Key Words: Coronary Artery Disease, Valvular Heart Disease.

\section{Introduction}

Coronary artery disease (CAD) have is commonly associated with valvular heart disease particularly in the developed western countries. The prevalence of degenerative aortic valve disease increases with age and it is the leading valvular condition accompanying CAD. Concomitant coronary artery disease has also been implicated in the operative morbidity and mortality of patients undergoing valve replacement surgery. After successful aortic valve surgery ischemic heart disease was found to be the cause of left ventricular dysfunction in certain patients.

The coronary angiography has been indicated as a routine procedure in the preoperative assessment of patients with valvular heart disease that meet the following criteria: males aged $>35$ years, pre-menopausal females aged $>35$ years with cardiovascular risk factors and post-menopausal females $(1,2)$ The procedure is justified by the diagnosis of coronary obstructions, especially the asymptomatic ones and the significant prevalence of coronary artery disease $(\mathrm{CAD})$ in these patients. 


\section{Materials And Methods}

The study entitled "Clinical Profile Of Coronary Artery Disease In Valvular Heart Disease Undergoing Valve Replacement Surgery" has been conducted in Department Of Cardiology, Gauhati Medical College, Guwahati from December 2011 to November 2013.

All consecutive cases of valvular heart disease, who were scheduled for valve surgery were taken for the present study.

\section{Inclusion Criteria :-}

1. Men $\geq 35$ years

2. Women $\geq 35$ years with coronary risk factors

3. Postmenopausal women

4. Patients with chest pain, objective evidence of ischemia, decreased left ventricular systolic function, history of coronary artery disease and coronary risk factors.

(ACC/AHA guideline of valvular heart disease ; 2008)(2)

\section{Exclusion Criteria :-}

1. Valvular heart disease resulting directly from ischaemic heart disease (for example papillary muscle dysfunction).

2. Patients undergoing emergency valve surgery for acute AR, aortic dissection, or endocarditis with hemodynamic instability.

(ACC/AHA guideline of valvular heart disease ; 2008)(2)

The baseline clinical characteristics which were analyzed were the age, gender, hypertension (blood pressure $>140 / 90 \mathrm{~mm} \mathrm{Hg}$ and/ or those already taking treatment for hypertension), diabetes mellitus (fasting blood glucose $>126 \mathrm{mg} / \mathrm{dL}$ and/or postprandial blood glucose $>200 \mathrm{mg} / \mathrm{dL}$ and those who were on treatment for diabetes mellitus), smoking status, dyslipidemia (cholesterol $>200 \mathrm{mg} / \mathrm{dL}$ and/or triglycerides $>200 \mathrm{mg} / \mathrm{dL}$ and/or ,LDL $>130 \mathrm{mg} / \mathrm{dL}$ and/or $\mathrm{HDL}<40 \mathrm{mg} / \mathrm{dL}$ )\& Body mass Index(BMI). Routine haematological investigation obtained for all patients.

All patients underwent2D- Doppler echocardiography to asses morphology of valve, severity of lesion, pulmonary artery pressure and left ventricular function. The echocardiogram was used to define the criteria of rheumatic and non-rheumatic etiology.

To define the rheumatic valvularcardiopathy, the following criteria were considered:

1) In the mitral valve: thickening of the free border of the leaflets with or without commissure fusion and of the subvalvular apparatus with reduced mobility and posterior leaflet fixation, and

2) In the aortic valve: cusp thickening, from the border to the base.

For the non-rheumatic valvularcardiopathy, the following degenerative disease criteria were considered:

1) In the mitral valve: leaflet thickening with preserved mobility in the free border;

2) In the aortic valve: fibro-calcific degeneration, characterized by calcification that started on the cusp bases and went towards their borders, and

3) In the bicuspid aortic valve: visualization of only two leaflets with cusp thickening.

Selective coronary arteriography was performed by the Judkins technique .Coronary artery stenosis was assessed as the maximum percentage reduction in luminal diameter, seen in any one of at least three different projections, as compared with the diameter of the vessel proximal to the obstruction. Significant coronary artery disease was considered to be present if one or more coronaries showed $50 \%$ or more luminal stenosis.

The patients were divided into two groups based on presence of CAD. A comparison of clinical paramaters between two groups were obtained. Informed consent were taken from all patients.

Statistical analysis :- All data were analyzed using SPSS (17 version) software. Continuous variables were analyzed and expressed as mean \pm SD and differences in frequency distribution of risk factors were tested using chi-square analysis. A p-value $<0.5$ was considered significant. 


\section{Result}

A total of 126 valvular disease cases were included in the study. Mean age of patients were 50.59 years. In our study, $50.79 \%$ had isolated mitral valve disease, $19.05 \%$ were isolated aortic valve disease, and combined mitral and aortic valve lesion were present in $30.16 \%$ of patients.

Isolated mitral valve disease was more common in women $(\mathrm{p}=0.002)$; while isolated aortic valve disease in men $(\mathrm{p}=0.001)$. Combined mitral and aortic valve disease was almost equal in frequency in both group $(\mathrm{p}=0.561)$. Of the 126,108 cases were rheumatic valvular heart disease $(85.71 \%)$ and 18 were nonrheumatic valvular heart disease (14.29\%).

In our study, among the mitral valve disease patients typical angina was present in $9.3 \%$ of the patients, of whom $33.33 \%$ had significant coronary artery disease and none of the patients had coronary artery disease in no angina group; among the isolated aortic valve disease typical angina was present in $70.83 \%$ of patients and of whom only $23.52 \%$ had significant coronary artery disease, while $33.33 \%$ of patients in no angina group had coronary artery disease; $36.84 \%$ patients had typical angina among the combined lesion but only $14.28 \%$ had significant coronary artery disease and $10 \%$ had coronary artery disease in patients without angina.

Overall frequency of coronary artery disease among mitral, aortic, and combined mitral and aortic valve lesion is $3.13 \%, 33.33 \%$ and $21.05 \%$ respectively. In comparison to mitral valve disease, aortic valve disease and combined lesion having significantly high chances of coronary artery disease $(\mathrm{p}=0.001)$.(Figure 1$)$

In our study, total 18 patients had coronary artery disease, out of them 14 had single vessel disease, 2 had double vessel disease and 2 had left main disease. None of the patient had triple vessel disease.

Among the single vessel disease, 8 patients had left anterior descending artery lesion, 2 had left circumflex lesion and 4 had right coronary artery disease. If we see the frequency of artery involvement, then left anterior descending artery was affected in 8 patients, 6 had right coronary artery disease, left main was involved in 4 patients, and 2 had left circumflex lesion.(Figure 2)

On comparing the clinical characteristic of patients with CAD from those without having CAD,we observed that, mean age of the patients with coronary artery disease $(59.45 \pm 10.58)$ are significantly high in comparison to without coronary artery disease $(48.92 \pm 6.57)$. Among coronary artery disease group $66.67 \%$ were male, $33.33 \%$ were females; while among without coronary artery disease group male and female were $51.85 \%$ and $48.15 \%$ respectively $(\mathrm{p}=0.243$ ). Moreover patients with CAD are more likely to present with typical angina,higher incidence of aortic valve disease, more likely to be non rheumaticetiology.Coronary artery disease group also had significantly high prevalence of diabetes mellitus, hypertension, and dyslipidemia ( $\mathrm{p}$ value of $<0.001$ for each); it was insignificant for smoking $(\mathrm{p}=0.081)$. atrial fibrillation was insignificantly associated with coronary artery disease $(\mathrm{p}=0.102)$. (Figure 3$)$

\section{Discussion}

This study was carried out to study the clinical profile of patients with Coronary Artery disease in patients with valvular heart disease undergoing surgery in Gauhati Medical College, Guwahati .

In our study,mitral valve disease is significantly more common in patients without coronary artery disease $(57.41 \%)$ than in patients with coronary artery disease $(11.11 \%)$; while aortic valve lesion is significantly more frequent in coronary artery disease (44.44\%) group than without coronary artery disease $(14.81 \%)$. Combined valve lesion is insignificantly high among patients with coronary artery disease $(44.44 \%)$ than patients without coronary artery disease $(27.78 \%)$.The frequency of rheumatic valvular heart disease is significantly high among patients without coronary artery disease $(90.74 \%)$ than in patients with coronary artery disease (55.56\%); while non-rheumatic valve lesion are significantly more common with coronary artery disease $(44.44 \%)$ patients than without coronary artery disease $(9.26 \%)$.

Our results are almost similar to previous studies. Elliott $\mathrm{H}$ et al (1970) have found overall 13\% incidence of significant coronary artery disease with $17.7 \%$ prevalence of coronary artery disease inaortic valvular disease patients(3).Moraski RE et al ( 1976) found 46\% prevalence of significant coronary artery disease in severe aortic stenosis patients(4).In patients with severe calcific aortic stenosis Hancock EW et al (1977) found 56\% prevalence of significant coronary artery disease(5).. Baxter RH et al (1978) found 20\% prevalence of coronary artery disease in valvular heart disease patients; the incidence of coronary artery disease was almost identical in the mitral and aortic groups(22\% and $17 \%$, respectively)(6).29\% prevalence of coronary artery disease was seen by Morrison GW et al (1980) invalvular heart disease patients; Isolated mitral valve disease, isolated aortic valve disease and combined mitral and aortic valve disease was present in $40 \%, 38 \%$ and $22 \%$ respectively; Among isolated mitral valve disease 33\% patients had significant coronary lesion,among isolated aortic valve disease, $28 \%$ had significant coronary artery disease, among combined mitral and aortic valve disease, $24 \%$ had significant coronary artery disease; the prevalence of coronary artery disease was greater in patients with mitral valve disease than with aortic valve disease $(\mathrm{p}<0.05)$ or combined aortic and mitral valve disease ( $\mathrm{p}<0.01$ ), there being no difference between the two latter. In Indian study by Gupta KG et al 
(1990)have found the overall prevalence of coronary artery disease was 7\% among patients of valvular heart disease; its prevalence was $3 \%$ in mitral, $10 \%$ in aortic and $6 \%$ in combined mitral and aortic valve disease(7).A landmark Indian study by Jose VJ et al(2004) found $12.2 \%$ patients of rheumatic heart disease had significant coronary artery disease; in patients with mitral vale disease the prevalence was $13.5 \%$, while it was $15.3 \%$ in patients with aortic valve disease and $9 \%$ in those with combined mitral and aortic valve disease(8).

Our study have found significant difference of presence of diabetes mellitus (33\% and 5.5\%), hypertension (55\% and $13 \%)$ and dyslipidemia (66.67\% and $18.52 \%)$ in between patients with coronary artery disease than in patients without coronary artery disease, respectively. While patients with coronary artery disease have insignificantly higher number of smokers $(66 \%$ and $44 \%)$ than without coronary artery disease. When we compare our results with other study then Hancock EW et al, 1977 found that Serum cholesterol was raised in $23 \%$ with coronary artery disease as compared to $8 \%$ in patients without coronary artery disease(5). In a study by Morrison GW et al (1980) smokers tended to have significant coronary lesions more frequently, the differences did not reach levels of statistical significance(9).A study by Bozbas H et al (2004) found patients with coronary artery disease had significantly increased prevalence of diabetes mellitus (14.6\% vs. $4.5 \%$; $\mathrm{p}=0.02)$, hypertension $(36.6 \%$ vs. $16.4 \%$; $\mathrm{p}=0.003)$, smoking $(51.2 \%$ vs. $23.2 \%$; $\mathrm{p}=0.001)$ and family history of CAD $(39.5 \%$ vs. $20.0 \%$; $=0.01)$ compared to patients with normal coronary arteries; however, the prevalence of dyslipidemia was similar in both groups $(45.9 \%$ vs. $36.4 \%$; $=0.1)(10)$. A study by Kruczan DD et al (2008) have found in patients with coronary artery disease prevalence of hypertension was $(68 \%$ vs $36 \%$; $p<0.0003)$, diabetes mellitus $(27 \%$ vs $4,45 \%$; $\mathrm{p}<0.001)$, dyslipidemia ( $27 \%$ vs $8 \%$; $\mathrm{p}<0.003)$, family history of premature coronary artery diasease $(57 \%$ vs $46 \%$; $=0.3)$, smoking $(61 \%$ vs $47 \% ; \mathrm{p}=0.18)$ compared to patients without coronary artery disease $(11)$.

\section{Conclusion}

We conclude that coronary artery disease is more prevalent in non rheumatic aetiology and patients with CAD have higher incidence of angina and are more likely to have cardiovascular risk factors.

\section{Bibliography}

[1]. Pomerantzeff PM, Barbosa GV, Sousa $F^{\circ}$ BS, Brandão CMA, Ribeiro EJ, Costa FDA, et al. Diretrizes para a conduta dos pacientes com doenças das valvascardíacas. In: Portal Cardiol [online]; 2003. Disponívelem: http://publicacoes.cardiol.br/consenso/2003/site/036.asp.

[2]. Bonow RO, Carabello BA, Chatterjee K, de Leon AC Jr, Faxon DP, Freed MD, et al. 2008 focused update incorporated into the ACC/AHA 2006 guidelines for the management of patients with valvular heart disease: a report of the American College of Cardiology/American Heart Association Task Force on Practice Guidelines (Writing Committee to revise the 1998 guidelines for the management of patients with valvular heart disease). Endorsed by the Society of Cardiovascular Anesthesiologists, Society for Cardiovascular Angiography and Interventions, and Society of Thoracic Surgeons. J Am CollCardiol 2008; 52: e1-142

[3]. Elliott HC, and Louis AS. Incidence of significant coronary artery disease in rheumatic valvular heart disease. vol.25;401-404,apr.1970

[4]. Moraski RE, Russell RO Jr, Mantle JA, RackleyCE.Aortic stenosis, angina pectoris, coronary arterydisease. CathetCardiovascDiagn 1976; 2: 157-64.

[5]. Hancock EW. Aortic stenosis, angina pectoris, and coronary artery disease. Am Heart J 1977;93:382-93.

[6]. Baxter RH, Reid JM, McGuiness JB, Stevenson JG.Relation of angina to coronary artery disease inmitral and aortic valve disease. Br Heart J 1978;40: 918-22.

[7]. Gupta KG, Loya YS, Bhagwat AR and Sharma S: prevalence of significant coronary heart disease in valvular heart disease in Indian patients. Ind Heart J 42;357-59,1990

[8]. Jose VJ, Gupta SN, Joseph G, et al. Prevalence of coronary artery disease in patients with rheumatic heart disease in the current era. Indian Heart J. 2004;56:129-131.

[9]. Morrison GW, Thomas RD, Grimmer SF, Silverton PN, Smith DR. Incidence of coronary artery disease in patients with valvular heart disease. Br Heart J 1980;44:630 -7.

[10]. Bozbas H, Yildirir A, Kucuk MA, Ozugl A, Atar I, Sezgin A, et al. Prevalence of coronary artery disease in patients undergoing valvular operation due to rheumatic involvement. AnadoluKardiyolDerg 2004; 4: 223-6.

[11]. Kruczan DD, Silva NA, Pereira Bde B, et al. Coronary artery disease in patients with rheumatic and nonrheumatic valvular heart disease treated at a public hospital in Rio de Janeiro. ArqBrasCardiol. 2008;90:197-203 
Figure 1: Distribution of valvular lesion among CAD and No CAD patients

\begin{tabular}{|l|l|l|}
\hline Variables & No CAD $(\mathrm{N}=108)$ & CAD $(\mathrm{N}=18)$ \\
\hline Mitral & $62(57.41 \%)$ & $2(11.11 \%)$ \\
\hline Aortic & $16(14.81 \%)$ & $8(44.44 \%)$ \\
\hline Mitral + Aortic & $30(27.78 \%)$ & $8(44.44 \%)$ \\
\hline
\end{tabular}

Figure 2: Bar chart showing distribution of CAD

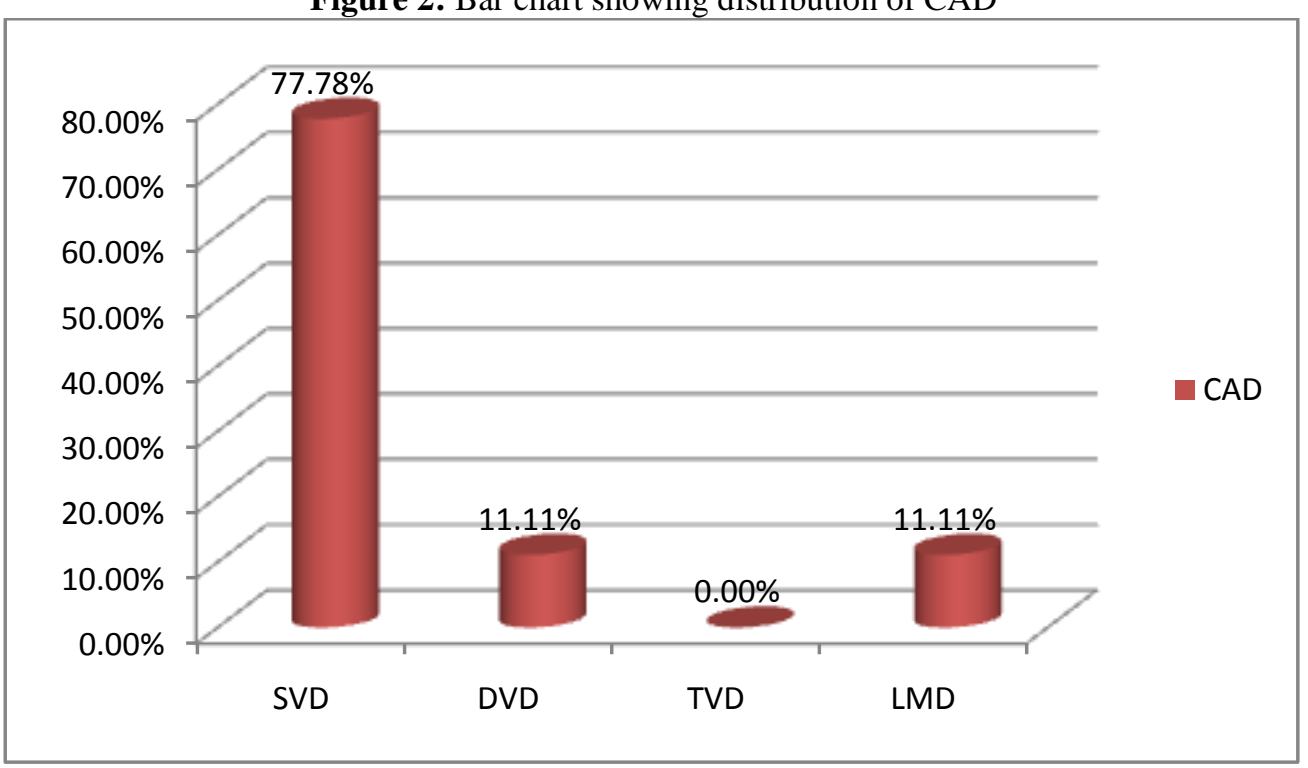

Figure 3: Clinical Characteristics Of CAD And No CAD Population

\begin{tabular}{|l|l|l|l|l|l|}
\hline Variables & No CAD & $\%$ & With CAD & $\%$ & P value \\
\hline Age (mean) & $48.92 \pm 6.57$ & & $59.45 \pm 10.58$ & & 0.001 \\
\hline Male & 56 & 51.85 & 12 & 66.67 & 0.243 \\
\hline Female & 52 & 48.15 & 6 & 33.33 & 0.234 \\
\hline Typical Angina & 25 & 23.15 & 12 & 66.67 & 0.001 \\
\hline Atypical Angina & 7 & 6.48 & 3 & 16.67 & 0.074 \\
\hline No Angina & 76 & 70.37 & 3 & 16.67 & 0.001 \\
\hline Mitral Disease & 62 & 57.41 & 2 & 11.11 & $<0.001$ \\
\hline Aortic Disease & 16 & 14.81 & 8 & 44.44 & 0.003 \\
\hline Combined Lesion & 30 & 27.78 & 8 & 44.44 & 0.154 \\
\hline Rheumatic etiology & 98 & 90.74 & 10 & 55.56 & 0.001 \\
\hline $\begin{array}{l}\text { Non-rheumatic } \\
\text { etiology }\end{array}$ & 10 & 9.26 & 8 & 44.44 & 0.001 \\
\end{tabular}

